\title{
EGAR, A Food Protein-Derived Tetrapeptide, Reduces Seizure Activity in Pentylenetetrazole-Induced Epilepsy Models Through $\alpha$-Amino-3-Hydroxy-5-Methyl-4-Isoxazole Propionate Receptors
}

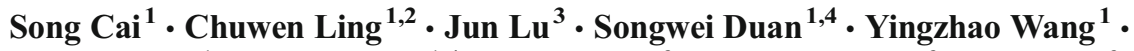 \\ Huining Zhu ${ }^{1} \cdot$ Ruibang Lin ${ }^{1,4} \cdot$ Liang Chen ${ }^{3} \cdot$ Xingchang Pan $^{3} \cdot$ Muyi Cai $^{3}$. \\ Huaiyu $\mathrm{Gu}^{1,5}$
}

Published online: 25 October 2016

(C) The American Society for Experimental NeuroTherapeutics, Inc. 2016

\begin{abstract}
A primary pathogeny of epilepsy is excessive activation of $\alpha$-amino-3-hydroxy-5-methyl-4-isoxazole propionate receptors (AMPARs). To find potential molecules to inhibit AMPARs, high-throughput screening was performed in a library of tetrapeptides in silico. Computational results suggest that some tetrapeptides bind stably to the AMPAR. We aligned these sequences of tetrapeptide candidates with those from in vitro digestion of the trout skin protein. Among salmonderived products, Glu-Gly-Ala-Arg (EGAR) showed a high biological affinity toward AMPAR when tested in silico. Accordingly, natural EGAR was hypothesized to have anticonvulsant activity, and in vitro experiments showed that EGAR selectively inhibited AMPAR-mediated synaptic transmission without affecting the electrophysiological properties of hippocampal pyramidal neurons. In addition, EGAR reduced
\end{abstract}

Muyi Cai

caimuyi@vip.sina.com

$\triangle$ Huaiyu Gu

471071491@qq.com

1 Department of Anatomy, Zhongshan School of Medicine, Sun Yat-Sen University, Guangzhou 510080, China

2 School of Public Health, Sun Yat-Sen University, Guangzhou, Guangdong 510080, China

3 Research Center of Protein and Functional Peptides, China National Research Institute of Food and Fermentation Industries, Beijing 100015, China

4 Guanghua School of Stomatology, Sun Yat-Sen University, Guangzhou, Guangdong 510080, China

5 Guangdong Province Key Laboratory of Brain Function and Disease, Zhongshan School of Medicine, Sun Yat-sen University, 74 Zhongshan 2nd Road, Guangzhou 510080, China neuronal spiking in an in vitro seizure model. Moreover, the ability of EGAR to reduce seizures was evaluated in a rodent epilepsy model. Briefer and less severe seizures versus controls were shown after mice were treated with EGAR. In conclusion, the promising experimental results suggest that EGAR inhibitor against AMPARs may be a target for antiepilepsy pharmaceuticals. Epilepsy is a common brain disorder characterized by the occurrence of recurring, unprovoked seizures. Twenty to $30 \%$ of persons with epilepsy do not achieve adequate seizure control with any drug. Here we provide a possibility in which a natural and edible tetrapeptide, EGAR, can act as an antiepileptic agent. We have combined computation with in vitro experiments to show how EGAR modulates epilepsy. We also used an animal model of epilepsy to prove that EGAR can inhibit seizures in vivo. This study suggests EGAR as a potential pharmaceutical for the treatment of epilepsy.

Keywords Epilepsy · Tetrapeptide $\cdot$ AMPARs $\cdot$ Drug · Nervous systems

\section{Introduction}

Epilepsy, characterized by recurring, unprovoked seizures, representing abnormal synchronous activity of neurons in a focal area of the brain or throughout the entire brain [1], is a common neurologic disorder that is estimated to affect $>50$ million patients worldwide [2]. In fact, although $>15$ antiepileptic drugs are currently available in most countries, $20 \%$ to $30 \%$ of persons with epilepsy do not achieve adequate seizure control with any drug and are therefore considered to be "drug-resistant" [3].

There is now extensive research on epilepsy that is directed towards developing safer and more effective new drugs that 
are capable of interfering with excitatory neurotransmission, which plays a pivotal role in regulating neuronal activity in both physiological and pathological conditions in the mammalian central nervous system [4], especially with glutamatergic transmission mediated by $\alpha$-amino-3-hydroxy-5-methyl4-isoxazole propionate receptors (AMPARs) [5]. It has been well established that excessive activation of glutamate receptors in AMPARs is one of the major causes of $\mathrm{Ca}^{2+}$ overload in cells, consequently triggering seizures and requiring maintenance procedures associated with epilepsy [6]. AMPA itself, administered systemically or by cerebroventricular infusion, is able to elicit seizures in preclinical models, hence suggesting a role for AMPARs in the generation of seizures [7], and making AMPARs an attractive drug target [8]. $N$-methyl-Daspartic acid (NMDA) receptors (NMDARs) may also contribute to epileptiform activity, but an NMDARs blockade is not sufficient to eliminate epileptiform discharges [1].

Based on previous publications, AMPAR antagonists may have therapeutic potential as appropriate drugs for the prevention and treatment of epilepsy [8]. Agents that inhibit or decrease AMPAR activity have the potential to reduce excessive excitatory responses, providing neuroprotection and seizure suppression [9]. The prototypical competitive AMPAR antagonist 2,3-dihydroxy-6-nitro-7-sulfamoyl-benzo[f] quinoxaline shows activity in pentylenetetrazole (PTZ)-induced seizure models [10], but it has poor solubility, resulting in precipitation in the kidney at therapeutic plasma levels. Derivatives of 2,3-dihydroxy-6-Nitro-7-sulfamoyl-benzo[f] quinoxaline with polar constituents have improved solubility, but these compounds exhibit decreased blood-brain barrier penetration [11]. Perampanel, the first approved antiepileptic drug to inhibit glutamate receptors selectively, exerts a highly selective and strong inhibitory effect on AMPAR activity, in preclinical studies [12]. In animal models of acute and chronic seizures, perampanel was shown to have broad-spectrum antiseizure effects by elevating the after discharge threshold and inhibiting seizure propagation $[12,13]$. Thus, we chose peptides that are highly degradable and absorbable in mammals as our candidate molecules to inhibit the excessive activation of AMPARs and treat epilepsy.

Currently, computational methods, such as molecular docking and molecular dynamic simulation, are routinely used to evaluate compounds for their ability to bind to proteins with well-defined binding sites [14]. The extracellular agonistbinding domain (S1S2 domain) of ionotropic glutamate receptors consists of 2 lobes with the agonist-binding pocket located between the 2 lobes $[15,16]$. The S1S2 domain is very important in understanding the physiological role of AMPARs and in developing useful therapeutic agents targeted to these widespread receptors. Under these circumstances, building a complete library of tetrapeptides may be a novel and highly efficient way of high-throughput screening for AMPAR antagonists.
While major dietary intervention has been applied to prevent diseases such as diabetes and heart disease, the potential impact of diet on neurologic disorders has been neglected. During the last several decades, fish proteins have been widely studied, and their various multifunctional properties have been well described [17]. Salmon is a popular food worldwide, and it is considered to be healthy because of the fish's high nutritional value and pharmacologic activity. Salmon skin, the underutilized by-product from salmon processing, consists of notable amounts of collagenous protein.

It is well known that, in protein, it is bioactive peptides that act out the biological activity. Bioactive peptides have been defined as specific protein fragments that have a positive impact on body functions or conditions and may ultimately influence health $[18,19]$. Since the first bioactive peptide was revealed by Mellander in 1950 [20], the potential physiological functions of bioactive peptides derived from dietary protein have aroused scientific interest and attention [21, 22]. Some peptides can influence higher brain functions such as learning and memory in animals [23].

Theoretically, bioactive peptides can be released from dietary protein through digestion in the gut, while the amount of peptides, however, is too small to induce any significant effects. In contrast, the enzymatic hydrolysis of dietary proteins offers a rapid and reproducible method for the production of considerable bioactive peptide fractions, and they are likely to become potential health-beneficial food ingredients or nutraceutical preparations [24]. Thus, the most ideal tetrapeptide candidate for use as an antiepilepsy agent is considered to not only show great affinity for the AMPAR in silico, but also be a salmon skin collagen peptide (SSCP).

In this work, we report the in silico, in vitro, and in vivo activity of Glu-Gly-Ala-Arg (EGAR), a bioactive tetrapeptide SSCP that acts as an antiepileptic agent. We provide evidence to support that, with solubility both in water and in lipid, EGAR is a novel AMPAR antagonist with anticonvulsant activity in experimental models.

\section{Materials and Methods}

\section{Materials}

Atlantic salmon (Salmo Salar L.) skin was donated by CF Haishi Biotechnology Ltd. Co. (Beijing, China). The salmon skin was washed twice with water and then stored in sealed plastic bags at $-20{ }^{\circ} \mathrm{C}$ until use. Reagents were purchased from the following sources: tetrodotoxin, picrotoxin (PTX), the disodium salt of 6-cyano-7-nitroquinoxaline-2, 3-dione (CNQX), 2-amino-5-phosphonovaleric acid (APV), NMDA, and AMPA were all purchased from TOCRIS Bioscience (Bristol, UK); papain and PTZ were from Sigma Aldrich (St. Louis, MO, USA); synthesized EGAR was from 
ChinaPeptides Co., Ltd (Shanghai, China). The EGAR stock solution consisted of $1 \mathrm{mg}$ lyophilized EGAR solubilized in $115 \mu$ l distilled water. The resulting stock solution was diluted in artificial cerebrospinal fluid (ACSF) (pH 7.2-7.4) to a final concentration of $100 \mu \mathrm{M}, 50 \mu \mathrm{M}, 20 \mu \mathrm{M}$, and $1 \mu \mathrm{M}$ EGAR.

\section{Animals}

The protocol described in the following was approved by the Animal Care and Use Committee of the Sun Yat-Sen University, and is in compliance with the National Institutes of Health guidelines for the use of experimental animals. C57BL/6 mice (15-20 g) were used in the experiment. The animals were housed at 20 to $22{ }^{\circ} \mathrm{C}$ in their individual cages, with free access to food and water. They were kept on a 12-h light/dark cycle.

\section{Peptide Library and Virtual Screening}

CycloPs was applied to generate a library of structures for tetrapeptides [25]. All $20 \mathrm{~L}$-amino acids that were in the generating section of the library, consisting of 160,000 tetrapeptides, were used. Then, tetrapeptides were built, and their structures were subjected to energy minimization through the MMFF94 force field to obtain the lowest-energy conformation prior to docking. Hydrogen atoms were added to all the tetrapeptide structure.

The virtual screening method as previously reported $[26,27]$. Briefly, standard precision of Autodock Vina was employed to screen the tetrapeptide library. The best docking pose of the compound was kept based upon binding energy score. Then, the top 500 compounds were selected for the molecular dynamic simulation for the deep screening. Finally, 11 compounds were selected and purchased for bioassays. And for EGAR, the top 1 was selected for the further research.

\section{Molecular Docking and Molecular Dynamics Simulation}

The structure of AMPAR (PDB code 3KG2 and 3DLN) was adopted for docking calculations $[15,28]$. Autodock 4 was used for automated molecular docking with the Lamarckian genetic algorithm [29]. The grid map with the Lamarckian genetic algorithm at $0.375 \AA$ was generated with the AutoGrid program to calculate the binding energies between the ligand and the receptor. Docking parameters were set to default values except for the number of genetic algorithm (GA) runs (200) and energy evaluations $(25,000,000)$. All docked conformations were clustered under a tolerance of $2 \AA$ for root mean square deviation (RMSD) and ranked according to docking energies at the end of each run.

The AMBER11 simulation suite was applied for molecular dynamic simulations and data analysis [30]. The all-atom point-charge force field (AMBER ff03) [31], showing a good balance in the balance between helix and sheet, was utilized to represent the peptides. The water solvent was explicitly represented by the TIP3P model [32]. The parameters for EGAR were generated as follows. After a geometry optimization at the $\mathrm{HF} / 6-31 \mathrm{G}^{* *}$ level, the electrostatic potential of EGAR was acquired at this level. The partial charges were derived by fitting the gas-phase electrostatic potential using the restrained electrostatic potential method [33], and other force parameters of the EGAR molecule were taken from the AMBER GAFF parameter set [34]. The missing interaction parameters in the ligand were generated using antechamber tools in AMBER. The system was first minimized using the steepest descent algorithms for 2000 steps. Then, we performed 5 ns molecular dynamics (MD) simulations for the system with the National (American) Pipe Thread (NPT) ensemble. The pressure was coupled to 1 bar with an anisotropic coupling time of $1.0 \mathrm{ps}$, and the temperature was kept at $300 \mathrm{~K}$ during the simulation, with a coupling time of $0.1 \mathrm{ps}$. The long-range electrostatic parameters were computed using the Particle-Mesh Ewald method [35]. SHAKE was utilized to constrain all bonds connecting hydrogen atoms [36], which enables a $2.0 \mathrm{fs}$ time step in the simulation. Two cut-offs of 0.8 and $1.2 \mathrm{~nm}$ were used for the evaluation of the nonbonded interactions. We then applied molecular mechanics generalized born surface area (MM-GBSA) to estimate the binding energies at $300 \mathrm{~K}$. In total, $192 \mathrm{AMD}$ Opteron (tm) Processor central processing units $(2.0 \mathrm{GHz})$ were used for the above computation.

\section{Binding Free Energy Calculations}

The binding free energies ( $\Delta$ Gbind) were computed with the MM-GBSA approach built in the AMBER program [37]. Generating multiple snapshots from an MD trajectory of the protein-ligand complex was the first step in the MM-GBSA method. Fifty snapshots were taken in total from the last 2-ns trajectory with an interval of 100 ps. The free energy was calculated in every snapshot for each molecular species (complex, receptor, and ligand) with the following equation [38]:

$\Delta$ Gbind $=$ Gcom - Grec-Glig

where Gcomp, Grec, and Glig are the free energies for the complex, receptor, and ligand, respectively. Each was estimated using the following equation:

$\Delta$ Gbind $=\Delta \mathrm{Emm}+\Delta \mathrm{Gsolv}-\mathrm{T} \Delta \mathrm{S}$

where $\Delta E m m$ is the molecular mechanics, the energy of the molecule expressed as the sum of the internal energy of the molecule plus the electrostatic and van der Waals interactions; $\Delta$ Gsolv is the solvation free energy of the 
molecule; $\mathrm{T}$ is the absolute temperature; and $\Delta \mathrm{S}$ is the entropy of the molecule. The molecular mechanics free energy was calculated in:

$\Delta \mathrm{Emm}=\Delta$ Eelec $+\Delta \mathrm{Evdw}+\Delta \mathrm{Eini}$

where $\Delta$ Eelec is the Coulomb interaction, $\Delta \mathrm{Evdw}$ is the van der Waals interaction, and $\Delta$ Eini is the sum of the bond, angle, and dihedral energies; in this case, $\Delta$ Eini $=0$. The solvation free energy was computed previously [39]:

$\Delta \mathrm{Gsolv}=\Delta \mathrm{GGB}+\Delta \mathrm{Gnp}$

where $\Delta$ GGB is a polar solvation contribution calculated by solving the generalized bloch (GB) equation for the MM_GBSA method [40]. $\Delta$ Gnp was the nonpolar solvation term, which was computed as follows:

$\Delta \mathrm{Gnp}=\gamma \Delta \mathrm{SASA}+\beta$

where $\gamma$ is the surface tension, set to $0.0072 \mathrm{kcal} /\left(\mathrm{mol} \AA^{2}\right)$, and $\mathrm{b}$ is a constant, set to 0 . SASA is the solvent accessible surface area $\left(\AA^{2}\right)$, estimated using the MOLSURF algorithm. The solvent prove radius was set to $1.4 \AA$, to define the dielectric boundary around the molecular surface.

The vibrational entropy contributions were then calculated by NMODE analysis [41]. Because of the high computational demand, only 50 snapshots were accepted for NMODE analysis. Each snapshot had a dielectric of 4rij (rij = distance between atoms $i$ and $j$ ) until the root mean square of the gradient vector was $<0.0001 \mathrm{kcal} /\left(\operatorname{mol} \AA^{2}\right)$.

\section{Identification of EGAR from SSCP}

Approximately $5 \mathrm{~kg}$ Atlantic salmon skin was soaked with $0.2 \% \mathrm{NaOH}(1: 3, \mathrm{w} / \mathrm{w})$ for $12 \mathrm{~h}$ to remove part of the fishiness. Then, the skin was minced and homogenized with distilled water $(1: 5, \mathrm{w} / \mathrm{w})$, to form a slurry. The $\mathrm{pH}$ of the slurry was adjusted to 7.0 with $\mathrm{NaOH}$, and hydrolyzed with neutral proteases (from Bacillus subtilis, enzyme:substrate ratio $1: 100$ ) at $50{ }^{\circ} \mathrm{C}$ for $5 \mathrm{~h}$. Then, papain was added in an enzyme:substrate ratio of 1:50 to continue hydrolysis at $60{ }^{\circ} \mathrm{C}$ for $2 \mathrm{~h}$. Hydrolysis was stopped by heating at $100{ }^{\circ} \mathrm{C}$ for $10 \mathrm{~min}$.

The resultant hydrolyzate was centrifuged (LG10-2.4A; Beijing LAB Centrifuge Co. Ltd, China), and the supernatant was filtered with ceramic membranes (Filter and Membrane Technology Co. Ltd, Fujian, China). Next, the purified liquid was condensed by an R-151 rota vapor (BUCHI Co. Ltd, Postfach, Switzerland) at $75{ }^{\circ} \mathrm{C}$ until the concentration of the condensed liquid was almost $30 \%$ solid content. Then, it was decolored with $20 \%$ active carbon at $55{ }^{\circ} \mathrm{C}$ for $1 \mathrm{~h}$. Finally, we obtained SSCP powder $(620 \mathrm{~g})$ after the resulting filtered liquid was spray dried in an L-217 spray dryer (Beijing Laiheng LabEquipment Co. Ltd, Beijing, China).

To analyze the amino-acid sequence of the major peptides in SSCP, the powder was dissolved in water at $2 \mathrm{mg} / \mathrm{ml}$, and it was separated by reverse phase highperformance liquid chromatography (HPLC) on an XBridge BEH130 C18 column $(4.6 \times 250 \mathrm{~mm}$; Waters, Milford, MA, USA) with a nonlinear gradient. Eleven major fractions were collected and subjected to a quadrupole time-of-flight mass spectrometer for sequence identification that was performed by the National Center of Biomedical Analysis (Beijing, China).

For quantification of resultant peptides, SSCP was dissolved in water at $1 \mathrm{mg} / \mathrm{ml}$; then, the solution was passed through a cation exchange column $(4.6 \times 250 \mathrm{~mm}$; BonnaAgela, Tianjin, China) to remove interferential peptides. The content of the resultant peptides in SSCP can be calculated by the peak area-standard curve in reverse phase HPLC.

\section{Brain Tissue Preparation}

Hippocampal slices were prepared from 2 to 3-week-old mice for whole-cell recording. Accordingly, mice were deeply anesthetized with $20 \%$ urethane before decapitation. Their brains were quickly removed, immersed in ice-cold ACSF containing (in $\mathrm{mM}$ ): $124 \mathrm{NaCl}, 2.5 \mathrm{KCl}, 2 \mathrm{CaCl}_{2}, 2 \mathrm{MgCl}_{2}, 1.25$ $\mathrm{NaH}_{2} \mathrm{PO}_{4}, 26 \mathrm{NaHCO}_{3}$, and 10 glucose, and saturated with $95 \% \mathrm{O}_{2} / 5 \% \mathrm{CO}_{2}$ to a $\mathrm{pH}$ of 7.2 to 7.4 . Brains were trimmed and mounted in the vibratome (Leica VT1000A; Wetzlar, Germany), and 350- $\mu \mathrm{m}$-thick coronal slices were cut. Then, slices were incubated at room temperature with ACSF for at least $1 \mathrm{~h}$ before recording.

\section{Primary Cell Culture}

Dissociated hippocampal cultures were prepared from SD rat embryos, according to previously published protocols [42]. Briefly, whole hippocampi were dissected from SD rats on postnatal days 0 to 3 . Tissue was trypsinized for $10 \mathrm{~min}$ at $37{ }^{\circ} \mathrm{C}$ and mechanically dissociated using siliconized glass pipettes. Cells were added to each of the dishes containing the glass coverslips prepared previously. After 3 to $4 \mathrm{~h}$, coverslips were transferred to the dishes. Cells were used for patch-clamp recordings between 9 and 14 days in vitro.

\section{Electrophysiology Experiments}

Hippocampal slices were transferred to a submerged recording chamber (Warner Instruments, Hamden, CT, USA). In the recording chamber, slices were perfused continuously at a rate of $3 \mathrm{ml} / \mathrm{min}$ with ACSF (see above). Whole-cell recordings from CA1 hippocampal neurons were made by experimenters who were blinded to the 
control and treatment groups. Neuron identification was carried out with infrared differential interference contrast microscopy (BX51 W; Olympus, Tokyo, Japan) by the morphology. Recording electrodes with resistances ranging between 6 and $9 \mathrm{M} \Omega$ were pulled from $1.5 \mathrm{~mm}$ $(\mathrm{OD}) \times 0.86 \mathrm{~mm}$ (ID) borosilicate micropipettes by a Flaming-Brown electrode puller (P-97; Sutter Instruments, Novato, CA, USA) using a 4-stage pull protocol. The electrode for recording was filled with an internal solution containing (in $\mathrm{mM}$ ): 140 potassium gluconate, $5 \mathrm{NaCl}, 1 \mathrm{CaCl}_{2}, 2 \mathrm{MgATP}^{2-}, 10$ EGTA, and 10 HEPES (pH 7.2-7.4). Whole-cell recording was performed also using an external solution containing (in $\mathrm{mM}$ ): $140 \mathrm{NaCl}$, $5 \mathrm{KCl}, 1.5 \mathrm{CaCl}_{2}, 1 \mathrm{MgCl}_{2}, 10$ HEPES, and 10 glucose (pH 7.2-7.4). Internal and external recording solutions were filtered for sterilization before use. Voltage-clamp recordings of excitatory postsynaptic currents (EPSCs) were evoked using a bipolar Teflon-insulated iridium-platinum microelectrode (David Kopf Instruments, Tujunga, CA, USA) at a frequency of $0.0167 \mathrm{~Hz}$. EPSCs were also recorded after the addition of $50 \mu \mathrm{M}$ D-APV to the ACSF to block the NMDAR-mediated component of the EPSCs, and $10 \mu \mathrm{M}$ CNQX was applied to the ACSF to block the AMPAR-mediated component of the EPSCs. The external bath solution was added, with $10 \mu \mathrm{M}$ PTX, to isolate miniature EPSCs (mEPSCs). The mEPSCs were also recorded after application of ACSF with $10 \mu \mathrm{M}$ CNQX plus $20 \mu \mathrm{M}$ EGAR and $50 \mu \mathrm{M}$ D-APV (an NMDAR antagonist) plus $20 \mu \mathrm{M}$ EGAR. By adding $10 \mu \mathrm{M}$ CNQX or $50 \mu \mathrm{M}$ D-APV to the ACSF, NMDAR-mediated or AMPAR-mediated mEPSCs were isolated.

Then, whole-cell recordings were performed from the hippocampal neuron culture. Coverslips containing hippocampal neurons were removed from the culture medium and were placed in a $30 \times 10$-mm polystyrene culture dish containing external solution. For NMDA current recordings, the external bath solution also contained $100 \mu \mathrm{M}$ NMDA. To record AMPA currents, $20 \mu \mathrm{M}$ AMPA was added to the external solution. For nominally zero magnesium experiments, $\mathrm{Mg}^{2+}$ was replaced by an osmotically equivalent concentration of $\mathrm{Na}^{+}$. In separate experiments we examined neuronal input resistance and action potential properties. Recordings were obtained with a multiclamp $700 \mathrm{~B}$ amplifier, filtered at $10 \mathrm{kHz}$, sampled at $200 \mu \mathrm{s}$; these recordings were recorded to a personal computer using pClamp10.2 software and were analyzed using an Axon Instruments Digidata $1440 \mathrm{~A}$ and pClamp10.2 (Molecular Devices, Sunnydale, CA, USA).

\section{PTZ-Induced Seizure Models}

To determine the identity of the EGAR that was putatively responsible for the antiseizure effect, we evaluated the degree of epilepsy in 40 PTZ-induced seizure models administered EGAR. EGAR was injected $30 \mathrm{~min}$ prior to PTZ. Animals were divided into 4 groups at random, with 10 in each group. Each group was administered with $0,1,10$, or $100 \mathrm{mg} / \mathrm{kg}$ EGAR, respectively. All animals had PTZ injected intraperitoneally at a dosage of $55 \mathrm{mg} / \mathrm{kg}$, a dose that produced clonic seizures in all of the control animals.

Thirty-min monitoring was performed to observe the behavior of mice immediately after PTZ injection [43]. Two well-trained observers who were blind to the results analyzed the behavior of the mice. The mice were placed in a clear plastic cage and were observed for $30 \mathrm{~min}$. The cage was thoroughly cleaned with wet/dry cloths and $70 \%$ ethanol to remove any olfactory cues between subjects. Animals that showed rearing and forelimb clonus or more severe behaviors (rearing, clonus, and falling) were defined as mice with limbic seizures [44]. As shown in Fig. 8, seizures were scored according to the following scale: 0 , no response; 1 , immobility; 2 , gustatory movements and scratching; 3 , tremor; 4 , head bobbing; 5 , rearing and forelimb clonus; 6 , rearing, clonus, and falling; 7, death.

\section{Statistics}

Values are presented as the mean \pm SEM. Additionally, $p<0.05$ was considered to be significant. All statistical analysis of the biological data was performed using $t$-tests, with the exception that the $K-S$ test was used to perform analysis of the cumulative probability data. SPSS 13.0 software (IBM, Armonk, NY, USA) was used for all of the statistical analyses.

\section{Results}

\section{EGAR Bound to the S1S2 Domain of AMPAR in silico}

To investigate the interaction between EGAR and the AMPAR, structural analyses were implemented. From the MD simulation, it could be seen that there were 3 strong hydrogen bonds between EGAR and the AMPAR [(Glu-OE1)219Arg, (Glu-OE2)-219Arg, Arg-73Gly] (Fig. 1A, B), which play an important role in the stability of the complex. To validate the stability of the simulation, the RMSD of the $\mathrm{C} \alpha$ of the complex versus the simulation time are shown in Fig. 1C. The values of the RMSD were approximately $1.75 \AA$, and the structure of the AMPAR seemed to stabilize after $2 \mathrm{~ns}$. We found that the hydrogen bonds, with an average of $<3.5 \AA$ between EGAR and residues Arg219 and Gly 73 of the AMPAR, make significant contributions to the binding affinity (Fig. 1D). A hydrogen-bond interaction is thought to form if the distance between the hydrogen donor and the acceptor is $<3.5 \AA$ [45]. Therefore, we believe that the H-bond 

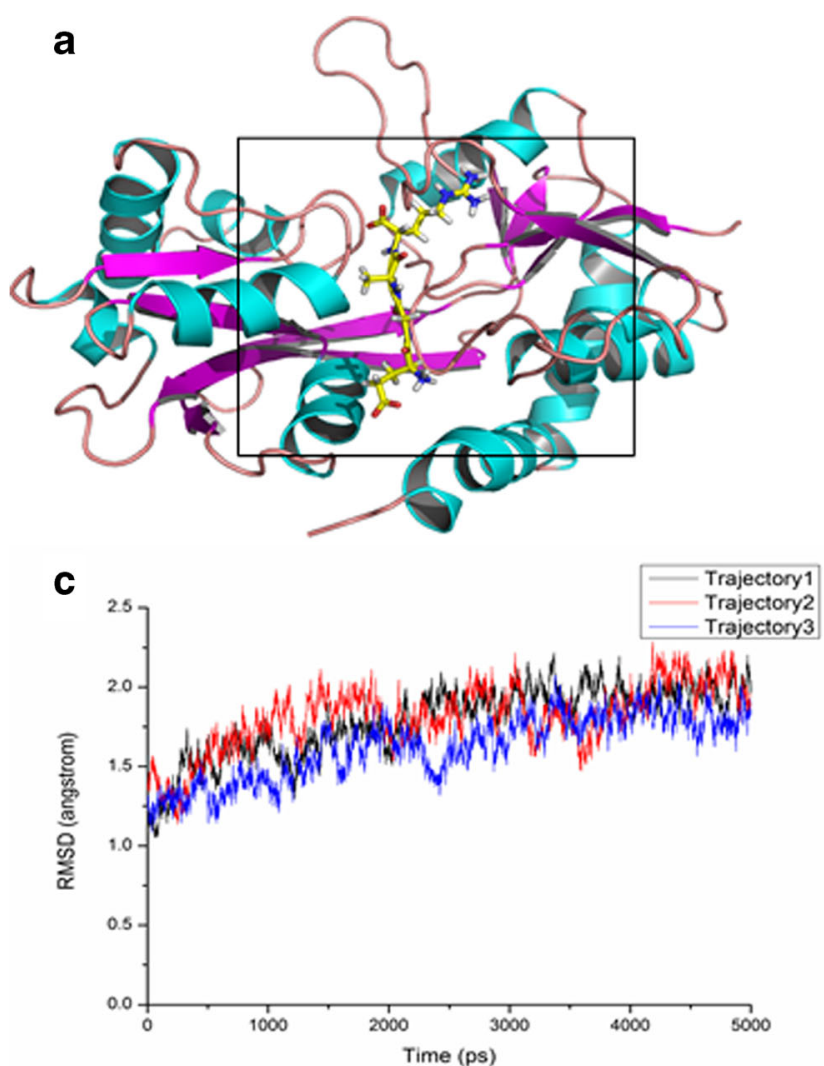

Fig. 1 Glu-Gly-Ala-Arg (EGAR) binds to $\alpha$-amino-3-hydroxy-5methyl-4-isoxazole propionate receptor (AMPAR) to form a stable complex in silico. (A) The combined conformation of the EGARAMPAR complex shows that EGAR binds to the S1S2 domain of AMPAR. (B) A small figure shows that the Arg219 and Gly 73 residues in the AMPAR formed hydrogen bonds with EGAR. (C) The distance between EGAR and AMPAR over 5000 ps simulations. The root mean

interaction between the EGAR and residues Arg219 and Gly 73 of the AMPAR stabilizes the EGAR-AMPAR complex in the MD simulation.

\section{MM_GBSA Calculations Proved that EGAR has High Affinity to AMPAR}

To explore the binding affinity of EGAR, the binding free energies were computed by means of the MM_GBSA in continuum solvent models, which was constructed based on a total of 250 snapshots taken from $15 \mathrm{~ns}$ to $20 \mathrm{~ns}$. Importantly, the calculated binding free energy of the complex was $-20.865 \mathrm{kcal} / \mathrm{mol}$, which indicates that EGAR has a high affinity to AMPAR. The electrostatic energy and the van der Waals energy of EGAR binding indicate that the binding process is thermodynamically favorable.

\section{EGAR was a Peptide of SSCP}

Eleven major fractions of SSCP on HPLC were collected (Fig. 2A). All of them had high peak area ratios $>1 \%$. The
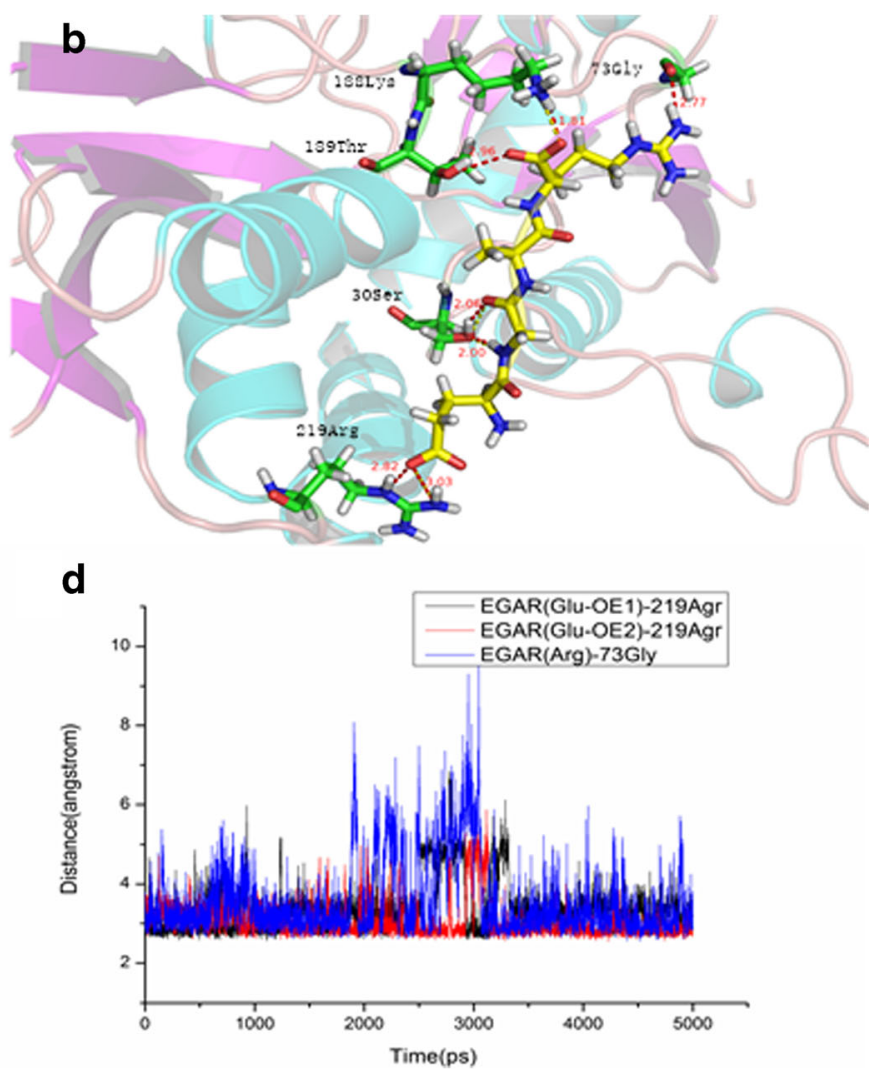

square deviation (RMSD) of the AMPAR remains steady at approximately $1.75 \AA$ in 3 repeated simulations, indicating that the complex is relatively stable. The red, blue, and black are 3 repeating trajectories for the MD simulations. (D) The time dependence of distances for 3 strong hydrogen bonds between EGAR and the AMPAR [(Glu-OE1) -219Arg, (Glu-OE2) -219Arg, Arg-73Gly]. The distance between the hydrogen donor and acceptor is less than $3.5 \AA$

fractions were subjected to a quadrupole time-of-flight mass spectrometer, to identify the amino-acid sequence. A total of 57 sequences were identified, and the sixth fraction was EGAR. This was also confirmed by matching the EGAR sequences with sequences from proteins of Atlantic salmon [46-49]. The mass spectrum of EGAR is shown in Fig. 2B.

\section{EGAR Inhibited CA1 EPSCs and mEPSCs in Mouse Hippocampal Slices}

In silico, we found that EGAR was able to combine AMPARs, a target for an antiepilepsy drug. Therefore, experiments were also performed to examine the effect of EGAR on CA1 stratum EPSCs evoked by Schaffer collateral stimulation in hippocampal slices. Consistent with virtual results, the application of EGAR reduced the EPSCs recorded in CA1 pyramidal cells (Fig. 3A). Different effects were elicited by 1 to $100 \mu \mathrm{M}$ EGAR in the presence of $10 \mu \mathrm{M}$ PTX to block $\gamma$ aminobutyric acid A receptors. On average, the mean amplitude of the EPSCs during the application of $1 \mu \mathrm{M}, 20 \mu \mathrm{M}$, $50 \mu \mathrm{M}$, and $100 \mu \mathrm{M}$ EGAR was $82.7 \%, 54.9 \%, 50.9 \%$, and 
a

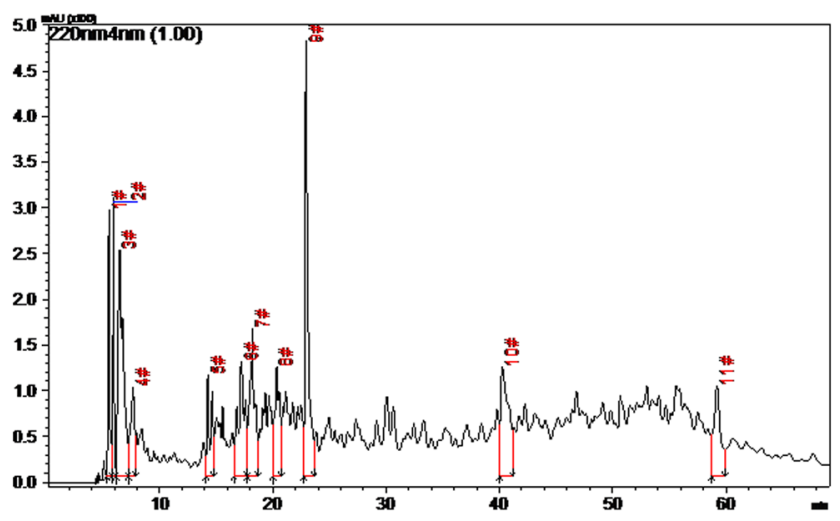

b

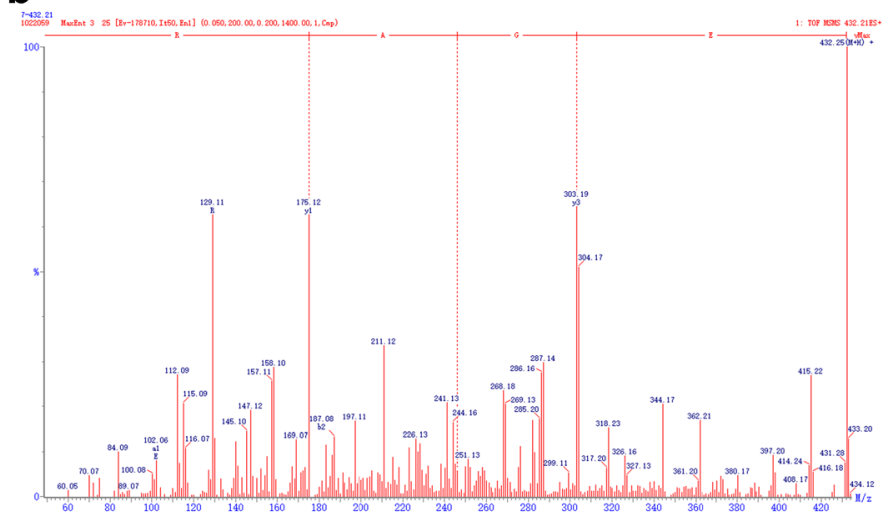

Fig. 2 Glu-Gly-Ala-Arg (EGAR) is a major peptide of salmon skin collagen peptide (SSCP). (A) The main fractions of SSCP. (B) Tandem mass spectrometry spectrum of EGAR

$46.4 \%$ in the control, respectively [Fig. 3B; paired $t$-test, $p>0.05, p<0.03, p<0.05$, and $p<0.05$, respectively, $(n=6)]$. As its concentration reached $20 \mu \mathrm{M}$, EGAR significantly inhibited the EPSCs in a dose-dependent manner. These data suggest that applying EGAR inhibits the Schaffer collateral pathway-evoked EPSCs in mouse hippocampal slices.

To determine whether the deficit in synaptic transmission caused by EGAR is presynaptic or postsynaptic, spontaneous mEPSCs were recorded from CA1 neurons in mouse hippocampal slices. In the presence of $1 \mu \mathrm{M}$ tetrodotoxin and $10 \mu \mathrm{M}$ PTX, to block action potentials and $\gamma$-aminobutryic acid A receptors, respectively, application of $1 \mu \mathrm{M}, 20 \mu \mathrm{M}$, $50 \mu \mathrm{M}$, and $100 \mu \mathrm{M}$ EGAR resulted in a decrease in the amplitude of mEPSCs (Fig. 3C). On average, the mEPSC amplitude was $88.5 \%, 46.4 \%, 46.8 \%$ and $42.3 \%$ in the control at $p>0.05, p<0.03, p<0.01$, and $p<0.01$, respectively ( $n=6$, paired $t$-test; Fig. $3 \mathrm{~F})$. A shift in the amplitude distribution occurred during exposure to $1 \mu \mathrm{M}, 20 \mu \mathrm{M}$, $50 \mu \mathrm{M}$, and $100 \mu \mathrm{M}$ EGAR at $p>0.05, p<0.05, p<0.05$, and $p<0.05$, respectively ( $n=6$, K-S test; Fig. $3 \mathrm{G})$. In contrast, the mean mEPSC frequency was unchanged at $p>0.05$, $p>0.05, p>0.05$, and $p>0.05$, respectively $(n=6$, paired $t$ test; Fig. 3D). The interevent interval distribution was not modified by $1 \mu \mathrm{M}, 20 \mu \mathrm{M}, 50 \mu \mathrm{M}$, or $100 \mu \mathrm{M}$ EGAR at $p>0.05, p>0.05, p>0.05, p>0.05$, respectively $(n=6$; Fig. 3E). Thus, the results generally prove that EGAR influences synaptic transmission postsynaptically.

\section{EGAR Selectively Inhibited the AMPAR-Mediated Component of CA1 EPSCs and mEPSCs in Mouse Hippocampal Slices}

To evaluate whether EGAR differentially inhibits AMPARs and NMDARs, we used a whole-cell voltage clamp to measure EPSCs carried via AMPARs or NMDARs, and examined the effects of EGAR. In the CA1 neurons of the hippocampal slices, the AMPAR-mediated EPSCs were reduced to
$50.2 \% \pm 7 \%$ of the control response after the application of ACSF in the presence of both $20 \mu \mathrm{M}$ EGAR and $50 \mu \mathrm{M}$ NMDAR blocker D-APV (Fig. 4A, C). In ACSF with $20 \mu \mathrm{M}$ CNQX (a competitive antagonist of non-NMDAR) to block the AMPAR-mediated EPSCs, $20 \mu \mathrm{M}$ EGAR did not affect the isolated NMDAR component of the EPSCs (Fig. 4B, D).

The selective inhibition of the AMPAR component of the EPSCs again supports a postsynaptic mechanism. To further distinguish between a pre- and postsynaptic site of action, we examined the effect of EGAR on AMPAR-mediated and NMDAR-mediated mEPSCs. We compared the frequency and amplitude of AMPAR-mediated mEPSCs at baseline and after applying $20 \mu \mathrm{M}$ EGAR for $5 \mathrm{~min}$. Twenty $\mu \mathrm{M}$ EGAR did not change the frequency of AMPAR-mediated mEPSCs $[p>0.05, t$-test $(n=6)$; Fig. 4E], and the interevent interval distribution was not modified $[p>0.05, \mathrm{~K}-\mathrm{S}$ test $(n=6)$; Fig. 4F]. However, $20 \mu \mathrm{M}$ EGAR significantly reduced the amplitude of AMPAR-mediated mEPSCs to $54.1 \%[p<0.05, t$-test $(n=6)$; Fig. 4G], and a significant shift in the amplitude distribution occurred $[p<0.05, \mathrm{~K}-\mathrm{S}$ test $(n=6)$; Fig. $4 \mathrm{H}$ ]. Consistent with our observation regarding the influence of EGAR on the EPSCs of NMDAR, EGAR did not inhibit the NMDAR-mediated component of CA1 mEPSCs (Fig. 5A), neither did it influence the amplitude $[p>0.05, t$-test $(n=6)$; Fig. $5 \mathrm{~B}]$ nor the frequency $[p>0.05$, $t$-test $(n=6)$; Fig. $5 \mathrm{C}$ ]. Changes in current amplitudes are typically the result of a postsynaptic alteration in receptor number or responsiveness. As a result, these data further support a specific deficit in postsynaptic responses after EGAR inhibition.

\section{EGAR Specifically Inhibited the AMPA Currents of Primary Cultured Hippocampal Neurons}

The activity of EGAR on AMPA-evoked and NMDAevoked currents was assessed using the patch-clamp 
Fig. 3 Glu-Gly-Ala-Arg (EGAR) inhibits CA1 excitatory postsynaptic currents (EPSCs) and miniature EPSCs (mEPSCs) in mouse hippocampal slices. (A) Sample traces of EPSCs recorded from CA1 pyramidal cells before and after treating with EGAR. (B) Bar graph of EPSC amplitudes shows there are significant difference between the control group and $20 \mu \mathrm{M}(* * p<0.03)$, $50 \mu \mathrm{M}(* * p<0.03)$, and $100 \mu \mathrm{M}$ $(* * p<0.03)$ EGAR treatments. (C) Sample mEPSC recording from CA1 pyramidal cells. (D)

The histogram depicts no change in $\mathrm{mEPSC}$ frequencies from EGAR-treated slices compared with the control group. (E) Cumulative probability of mEPSC interevent intervals shows no difference between control and EGAR treated slices.

(F) Bar graph showing a decrease in the amplitudes of mEPSC treated with $20 \mu \mathrm{M}(* * p<0.03)$, $50 \mu \mathrm{M}(* * p<0.03)$, and $100 \mu \mathrm{M}$ $(* * p<0.03)$ EGAR. $(\mathbf{G})$ Cumulative probability of mEPSC amplitudes shows a decrease in the amplitude between control and EGARtreated groups (K-S test, $p<0.05)$. Error bars represent \pm SEM a

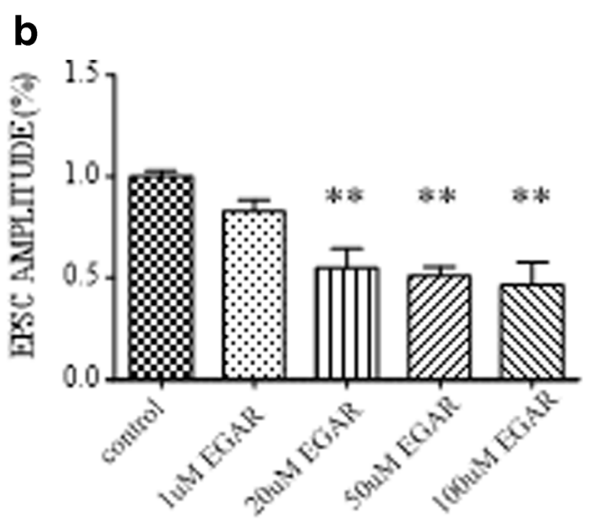

C

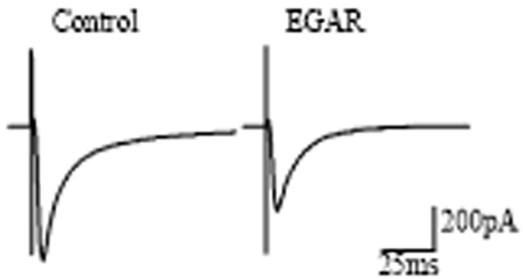

Coutrol
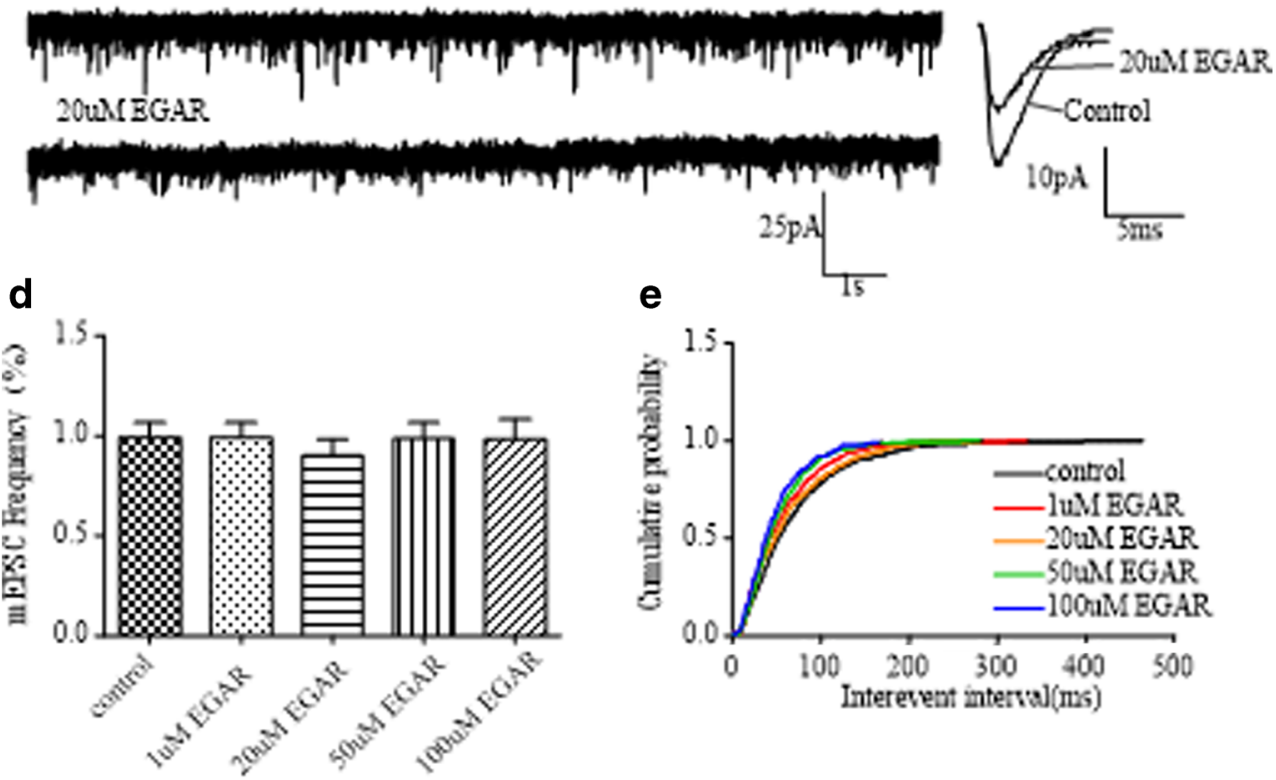

e
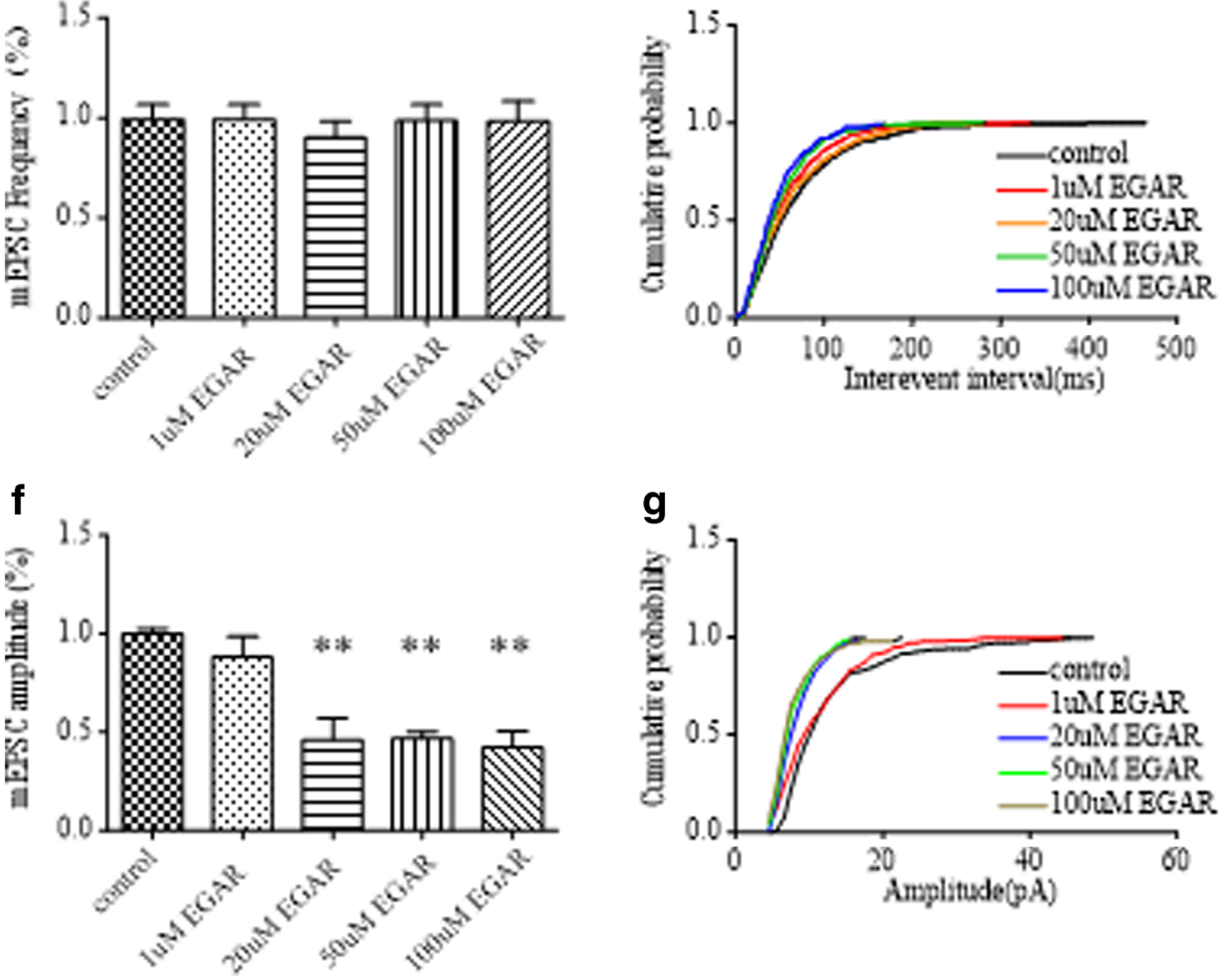

g

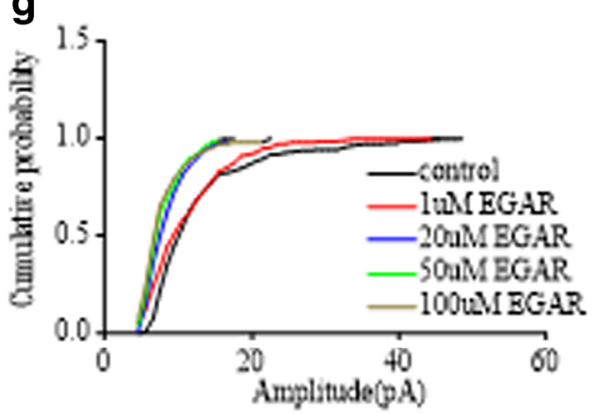

technique for dissociated hippocampal neurons grown in primary cultures. We recorded currents evoked by the application of AMPA $(20 \mu \mathrm{M})$, a selective agonist of the AMPA subtype of glutamatergic receptors, in the absence and presence of $20 \mu \mathrm{M}$ EGAR. In the cells, application of AMPA alone activated a rapidly decaying inward current followed by a prolonged component of lower amplitude (Fig. 6A). Following the test applications of AMPA and EGAR, the extracellular solution containing EGAR was replaced with control solution, and 5 min later, AMPA was applied alone (recovery; Fig. 6A). The degree of blocking in the peak currents produced by EGAR was expressed as the percentage reduction of the AMPA currents $(100 \%)$. In hippocampal neurons, AMPA-evoked currents were marginally affected and significantly reduced an average to $60.0 \%$ by the EGAR $(20 \mu \mathrm{M})$ application $[p<0.01$, paired $t$-test $(n=6)$; Fig. 6B]. The EGAR concentration of $20 \mu \mathrm{M}$ was chosen based on the above 


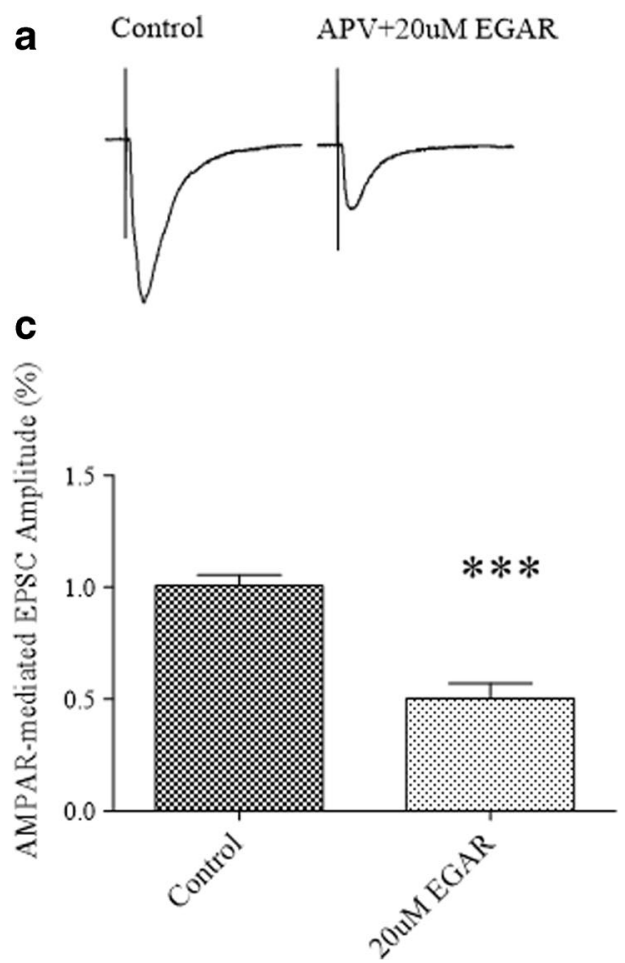

Fig. 4 Glu-Gly-Ala-Arg (EGAR) selectively inhibits the $\alpha$-amino-3hydroxy-5-methyl-4-isoxazole propionate receptor (AMPAR)-mediated component of CA1 excitatory postsynaptic currents (EPSCs). (A) Representative trace in CA1 of hippocampal slices before and after treatment with $50 \mu \mathrm{M}$ D-2-amino-5-phosphonovaleric acid [D-APV; an $N$-methyl-D-aspartate (NMDAR) antagonist] plus $20 \mu \mathrm{M}$ EGAR. (B) Representative traces in CA1 of hippocampal slices before and after treatment with $10 \mu \mathrm{M}$ 6-cyano-7-nitroquinoxaline-2,3-dione (CNQX; a

studies of the effective minimum concentration of EGAR for hippocampal slice function.

To further define the specificity of EGAR action on AMPA responses, we also examined the effect of EGAR on NMDAevoked currents. In contrast, EGAR $(20 \mu \mathrm{M})$ had no detectable effect on NMDA responses in 6 neurons in which EGAR partially inhibited AMPA currents $[p>0.05$, paired $t$-test $(n=6)$; Fig. 6C, D]. Based on these results, it is reasonable to assess that the reduction of the current is due to the block of the AMPAR-mediated component.

\section{EGAR Inhibited Low Magnesium-Induced Spiking in Primary Cultured Hippocampal Neurons}

To determine whether EGAR reduces neuronal hyperexcitability at concentrations comparable with those that inhibit AMPAergic EPSCs and mEPSCs in slices, we examined the effect of EGAR on the bursts of action potentials induced in cultured hippocampal neurons by nominally $\mathrm{Mg}^{2+}$-free extracellular solution [50, 51]. Cultured hippocampal neurons generally fire isolated action potentials when $\mathrm{Mg}^{2+}$ is present in the extracellular solution. When the extracellular solution contains no added $\mathrm{Mg}^{2+}$, the neurons fire bursts of action

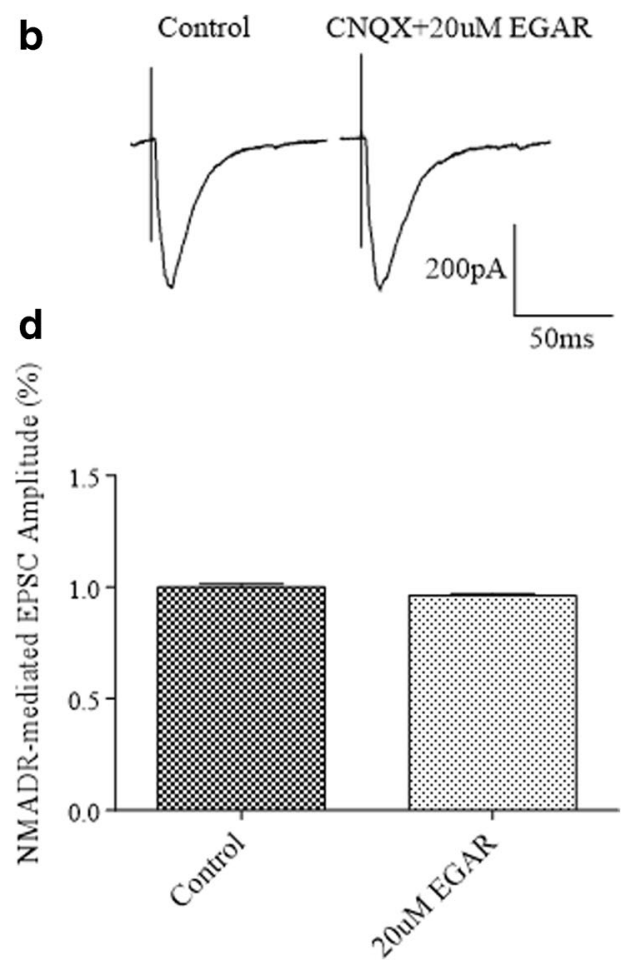

competitive antagonist of non-NMDAR) plus $20 \mu \mathrm{M}$ EGAR. (C) Bar graph demonstrating that co-treatment with $50 \mu \mathrm{M}$ D-APV and $20 \mu \mathrm{M}$ EGAR, results in a significant decrease in EPSCs amplitude compared with controls $[* * * p<0.01, t$-test $(n=6)]$. (D) Bar graph revealing no changes in EPSC amplitude when neurons are treated with $10 \mu \mathrm{M}$ CNQX in combination with $20 \mu \mathrm{M}$ EGAR $[p>0.05, t$-test $(n=6)]$. Error bars represent \pm SEM

potentials that are superimposed on a depolarizing shift; EGAR $(20 \mu \mathrm{M})$ decreased action potential bursting, which partially reverted to baseline bursting spike frequency after EGAR washout (Fig. 7A). The quantitative data show that $20 \mu \mathrm{M}$ EGAR significantly decreased action potential bursting on the basis of a comparison of the mean spike frequency from $4.4 \mathrm{~Hz} \pm 0.9 \mathrm{~Hz}$ to $1.5 \mathrm{~Hz} \pm 0.5 \mathrm{~Hz}$ in the same neuron before and after EGAR application $[p<0.05$, paired $t$-test $(n=6)$; Fig. 7B]. Thus, EGAR decreases neuronal hyperexcitability in cultured hippocampal neurons in the same effective concentration that decreases AMPAR-mediated EPSCs and mEPSCs in hippocampal slices.

\section{EGAR had no Significant Effect on Electrophysiological Properties of CA1 Neurons}

We also examined whether EGAR altered neuronal electrophysiological properties. After EGAR inhibition, a significant decrease was found in AMPAR-mediated mEPSCs. This deficit was not attributable to changes in the intrinsic properties of the neurons because average input resistance (Rin) (control 163.71 $\pm 7.29 \mathrm{M} \Omega$;EGAR, $164.57 \pm 9.96 \mathrm{M} \Omega$ ) and resting membrane potential 
$\mathbf{a}$

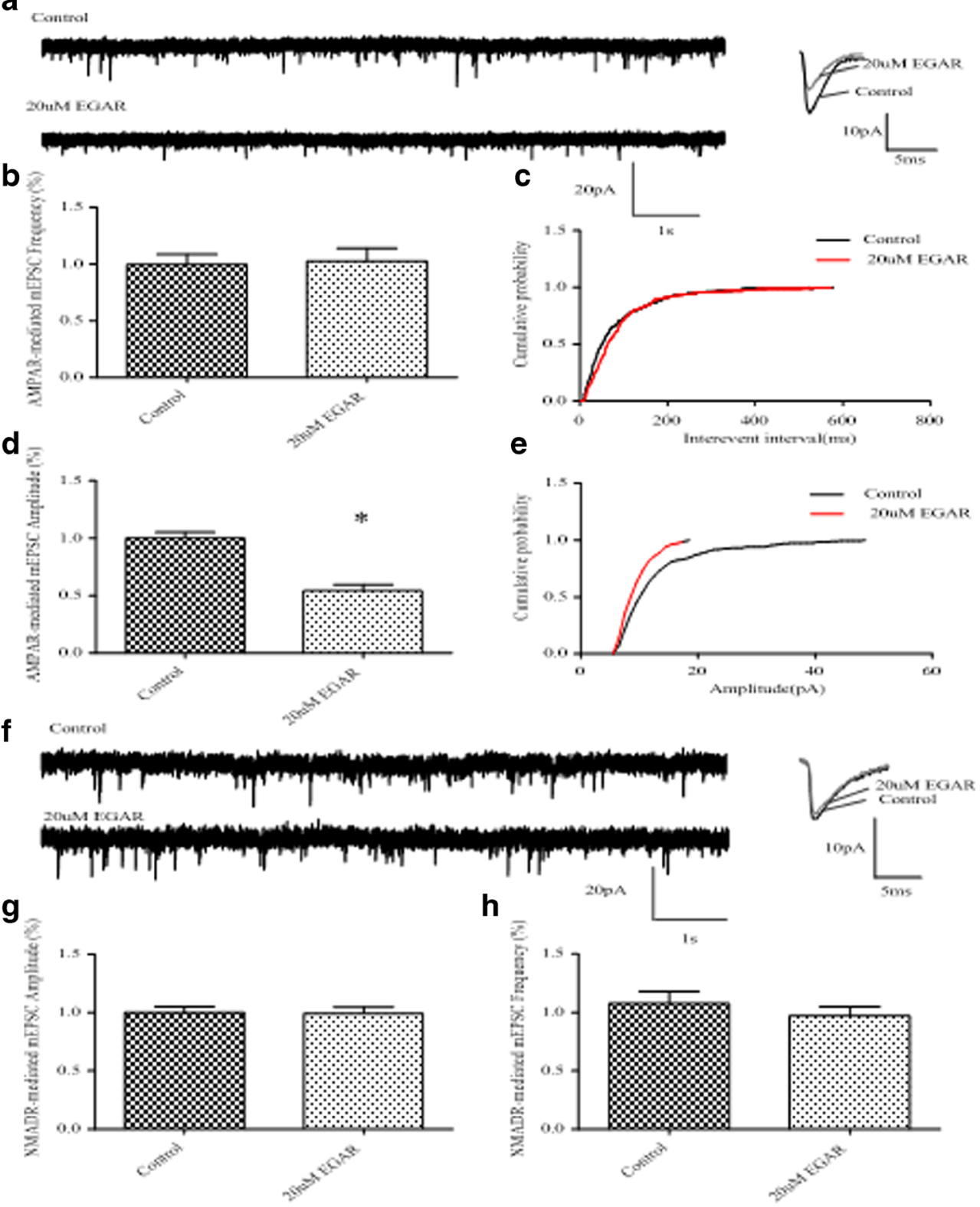

Fig. 5 Glu-Gly-Ala-Arg (EGAR) inhibits the $\alpha$-amino-3-hydroxy-5methyl-4-isoxazole propionate receptor (AMPAR)-mediated, not $\mathrm{N}$ methyl-D-aspartate (NMDAR)-mediated, component of CA1 miniature excitatory postsynaptic currents (mEPSCs). (A) Sample traces of AMPAR-mediated mEPSCs with and without EGAR treatment. $(\boldsymbol{B})$ Bar graph depicts no change in AMPAR-mediated mEPSC frequency from EGAR-treated neurons compared with controls $[\mathrm{p}>0.05, t$-test $(n=6)]$. (C) Cumulative probability of mEPSC interevent interval shows no difference in the frequency between control and EGARtreated groups [K-S test, $\mathrm{p}>0.05(\mathrm{n}=6)]$. $(\boldsymbol{D})$ Bar graph showing a decrease in the amplitude of AMPAR-mediated mEPSCs recorded from EGAR-treated neurons compared with controls [ ${ }^{*} \mathrm{p}<0.05$, $t$-test $\left.(\mathrm{n}=6)\right]$.

(Vrest) (control, $-68.57 \pm 2.16 \mathrm{mV}$; EGAR, $-65.6 \pm$ $1.23 \mathrm{mV}$ ) were unaffected by EGAR treatment. The application of EGAR alone was not accompanied by any significant change in the Rin, indicating that the intrinsic membrane properties of the cells were not affected by

(E) Cumulative probability of mEPSCs amplitude shows a decrease in the amplitude between control and EGAR-treated groups [K-S test, $\mathrm{p}<0.05$ $(\mathrm{n}=6)]$. $(\boldsymbol{F})$ Representative traces of mEPSCs recorded from the NMDAR-mediated component of CA1 neurons before and after treatment with NMDA $(100 \mu \mathrm{M})$ plus EGAR $(20 \mu \mathrm{M}) .(\boldsymbol{G})$ Bar graph indicates quantification of the effects of $100 \mu \mathrm{M}$ NMDA plus $20 \mu \mathrm{M}$ EGAR on NMDAR-mediated mEPSC amplitude. There were no significant differences between groups [p $>0.05$, $t$-test $(\mathrm{n}=6)]$. $(\boldsymbol{H})$ Bar graph indicates quantification of the effects of $100 \mu \mathrm{M}$ NMDA plus $20 \mu \mathrm{M}$ EGAR on NMDAR-mediated mEPSC frequency. There are no significant differences between groups $[p>0.05, t$-test, $(n=6)]$. Error bars represent \pm SEM

EGAR. In addition, membrane capacitances $(\mathrm{Cm})$ (control $20.64 \pm 0.79 \mathrm{pF}$; EGAR $19.07 \pm 0.67 \mathrm{pF}$ ) were similar. Furthermore, both action potential (AP) amplitudes (control $89.43 \pm 0.2 \mathrm{mV}$; EGAR $87.61 \pm 1.18 \mathrm{mV}$ ) and halfwidths (control $0.95 \pm 0.01 \mathrm{mV}$; EGAR $0.99 \pm 0.01 \mathrm{mV}$ ) 


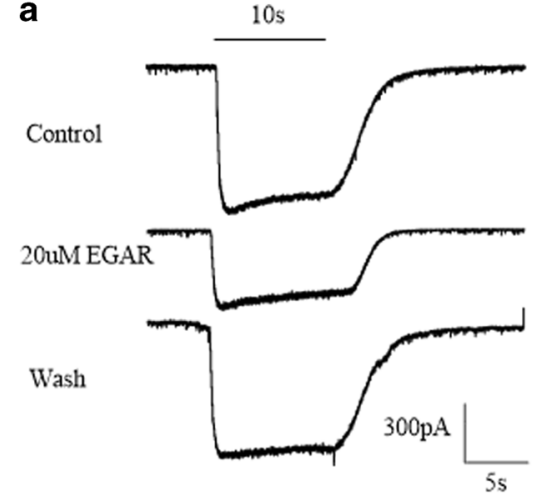

C

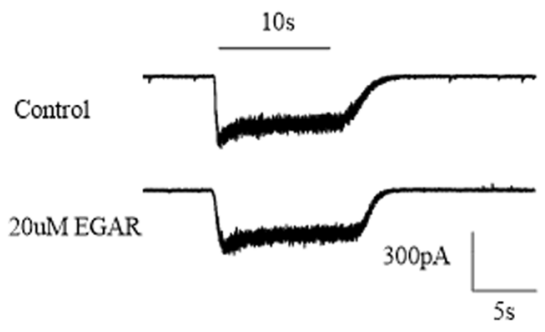

Fig. 6 Glu-Gly-Ala-Arg (EGAR) selectively inhibits $\alpha$-amino-3hydroxy-5-methyl-4-isoxazole propionate (AMPA) over $N$-methyl-Daspartate (NMDA) currents of primary cultured hippocampal neurons. (A) Representative traces of a patch-clamp experiment showing the inward current evoked by the application of $20 \mu \mathrm{M}$ AMPA and its reduction in the presence of EGAR. Horizontal bars show the duration of drug application. The upper and middle traces refer to the application of AMPA and the co-application of AMPA and EGAR. EGAR is applied at $20 \mu \mathrm{M}$. After the washout of EGAR, the AMPA responses partially b
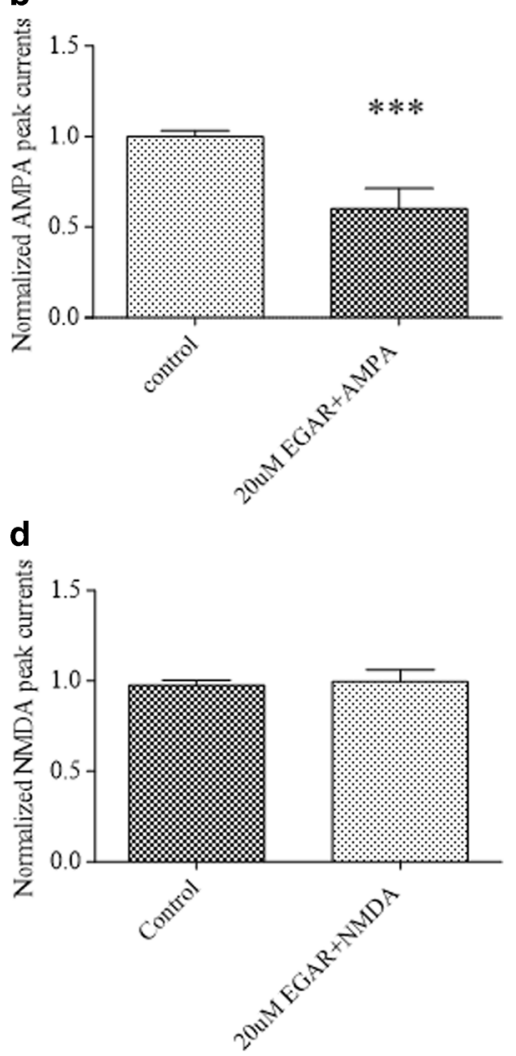

come back to the control level. The cell is voltage-clamped at $-70 \mathrm{mV}$. (B) Bar graph indicates the quantification of the effects of $20 \mu \mathrm{M}$ AMPA plus $20 \mu \mathrm{M}$ EGAR on AMPA peak currents. Differences between groups were significant $[* * * p<0.01, t$-test $(n=6)]$. (C) Effects of $20 \mu \mathrm{M}$ EGAR on NMDA-evoked currents. (D) Bar graph indicates quantification of the effects of $100 \mu \mathrm{M}$ NMDA plus $20 \mu \mathrm{M}$ EGAR on NMDA peak currents. There are no significant differences between groups $[p>0.05, t$-test $(n=6)]$. Error bars represent \pm SEM
Fig. 7 Glu-Gly-Ala-Arg (EGAR) inhibits low magnesiuminduced spiking in primary cultured hippocampal neurons. (A) Sample traces of low magnesium-induced spiking without and with the treatment of $20 \mu \mathrm{M}$ EGAR and its recovery after washout. (B) Bar graph indicates quantification of the effects of $20 \mu \mathrm{M}$ EGAR on low magnesium-induced spiking frequency. Differences between groups are significant $[* p<0.05$, $t$-test $(n=6)]$. Error bars represent \pm SEM a

$\mathrm{Mg}^{2}$ free

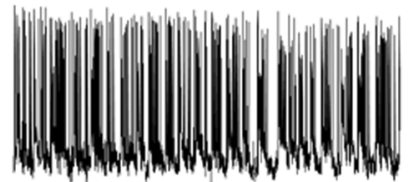

$\mathrm{Mg}^{2}$ free +20 um EGAR

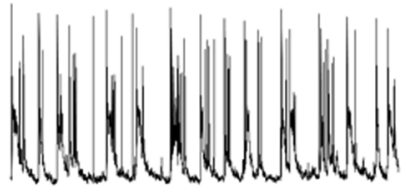

Wash

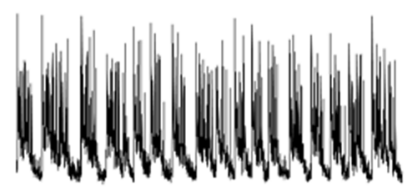

$20 \mathrm{mV}$

$10 \mathrm{~s}$ b

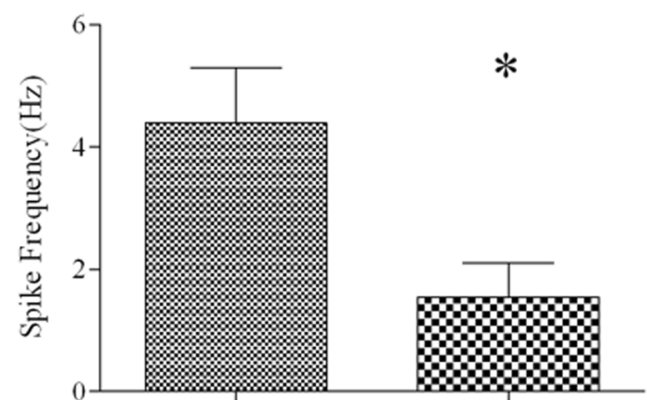


were unchanged. Finally, current step injections were used to determine the AP firing threshold and frequency. The AP firing thresholds were similar between control and EGAR-treated neurons (control $-46.26 \pm 0.5 \mathrm{mV}$; EGAR $-45.61 \pm 0.2 \mathrm{mV}$ ), and the frequency was unaltered after EGAR treatment (control $14.11 \pm 3.84 \mathrm{~Hz}$; EGAR $13.53 \pm$ $2.42 \mathrm{~Hz}$ ) (Table 1). Therefore, our data suggest that a decrease in the amplitude of AMPAR-mediated mEPSCs, after treatment with EGAR, will not alter the intrinsic or firing properties of individual neurons.

\section{EGAR Inhibited in vivo PTZ-Induced Generalized Convulsive Seizures}

To determine if EGAR inhibits seizures in this model, we gave EGAR intraperitoneally to mice $30 \mathrm{~min}$ before giving $55 \mathrm{mg} / \mathrm{kg}$ PTZ intraperitoneally. Mice in the control group developed rearing, clonus, and falling behavior within $4 \mathrm{~min}$. For comparison, $1 \mathrm{mg} / \mathrm{kg}, 10 \mathrm{mg} / \mathrm{kg}$, and $100 \mathrm{mg} / \mathrm{kg}$ groups remained at the stage of gustatory movements and scratching or tremor. Within $6 \mathrm{~min}$, the mice in the control group stayed in the same state, but seizures in the group of $100 \mathrm{mg} / \mathrm{kg}$ were significantly attenuated, although those in $1 \mathrm{mg} / \mathrm{kg}$ and $10 \mathrm{mg} / \mathrm{kg}$ groups became more severe than those displaying the behavior within $4 \mathrm{~min}$. All mice recovered within $8 \mathrm{~min}$ (Fig. 8B). Animals in the $100 \mathrm{mg} / \mathrm{ml}$ group did not show tremor and head bobbing, and those in the $10 \mathrm{mg} / \mathrm{ml}$ group did not show clonus and falling. The incubation period of the $1 \mathrm{mg} / \mathrm{kg}$ group and the $10 \mathrm{mg} / \mathrm{kg}$ group was 2 min longer than the control group. EGAR doses of 1,10 , and $100 \mathrm{mg} / \mathrm{kg}$ increased the seizure latency to 3.66, 4.11, and 4.59 min compared with the control group, in which the latency was 2.89 min (Fig. 8C). One conclusion may be that a light concentration of EGAR (1 and $10 \mathrm{mg} / \mathrm{ml}$ ) increases the incubation period. One hundred milligrams per ml EGAR can avoid severe behaviors and has a lower death rate.

Table 1 Effect of Glu-Gly-Ala-Arg (EGAR) on electrophysiological parameters of CA1 neurons

\begin{tabular}{lll}
\hline & Control & $20 \mu \mathrm{M}$ EGAR \\
\hline Vrest,mV & $-68.57 \pm 2.16$ & $-65.57 \pm 1.23$ \\
Rin, $\mathrm{M} \Omega$ & $163.71 \pm 7.29$ & $164.57 \pm 9.96$ \\
$\mathrm{Cm}, \mathrm{pF}$ & $20.64 \pm 0.79$ & $19.07 \pm 0.67$ \\
Amplitude,mV & $89.43 \pm 0.2$ & $87.61 \pm 1.18$ \\
AP half width,ms & $0.95 \pm 0.01$ & $0.99 \pm 0.01$ \\
Frequency, Hz & $14.11 \pm 3.84$ & $13.53 \pm 2.42$ \\
Threshold,mV & $-46.26 \pm 0.5$ & $-45.61 \pm 0.2$ \\
\hline
\end{tabular}

\section{Discussion}

Data presented in this study suggest that EGAR is a selective AMPAR antagonist with antiseizure activity in a preclinical epilepsy model.

In in silico studies, we demonstrated that a tetrapeptide, EGAR, is able to bind stably to AMPAR. Gating of the AMPAR channel occurs by agonist binding, including the natural ligand glutamate or the synthetic, but more selective, ligand AMPA, to a pocket produced by 2 globular protein domains forming the ligand-binding core that close around the agonist in a Venus flytrap or hinged-clamshell-type mechanism [52]. The subsequent movement of lobe 2 toward lobe 1 by approximately $20^{\circ}$ is the initial conformation change that triggers receptor activation [53]. EGAR, just like CNQX, the first potent and selective AMPAR antagonist [54], possibly exerts its blocking action by binding at the glutamate recognition site. Therefore, we think that adding EGAR may prevent the binding of agonists with AMPARs, and thus the receptor stays inactive.

In in vitro studies, we found that a narrow range of EGAR concentrations inhibited synaptic responses. A maximally effective EGAR concentration of $100 \mu \mathrm{M}$ inhibited CA1 EPSCs by $54.6 \%$ and CA1 mEPSCs by $57.7 \%$; lower concentrations produced less inhibition. The decrease in the amplitude of CA1 mEPSCs and the stability of the frequency of CA1 mEPSCs suggest that EGAR inhibits synaptic transmission postsynaptically. A potential postsynaptic mechanism based on the observed EGAR effect is AMPAR activity modification that was revealed in silico.

EGAR has differential effects on AMPAR and NMDAR responses. A postsynaptic effect is consistent with the tendency for $20 \mu \mathrm{M}$ EGAR to decrease depolarizations induced by a puffer of AMPA, an AMPAR agonist, in CA1 neurons. The inhibition we observed occurred independently of NMDAR activation because it occurred when D-APV blocked NMDARs, suggesting that EGAR is a selective AMPA receptor antagonist. These results were consistent with the defects in EPSCs and mEPSCs seen after the treatment of EGAR; in fact, these results demonstrate a result of the inhibition of AMPARs. A different effect on the AMPA or NMDA component of an EPSP or EPSC is evidence of a postsynaptic effect $[55,56]$. Despite the marked differences in NMDAR and AMPAR sensitivity to glutamate, presynaptic manipulations do not selectively affect 1 component [56]. AMPARs are thought to play a critical role in the propagation of seizures [57, 58], and are also likely to be involved in their initial triggering [59]. Selectivity of EGAR for AMPARs over NMDARs may also be an important feature clinically, as NMDAR antagonists are known to produce psychoactive effects, including schizophrenia-like symptoms and cognitive impairment [7]. In addition, because of underlying learning and memory, AMPARs move in and out of the synapse in a dynamic fashion in forms of synaptic 


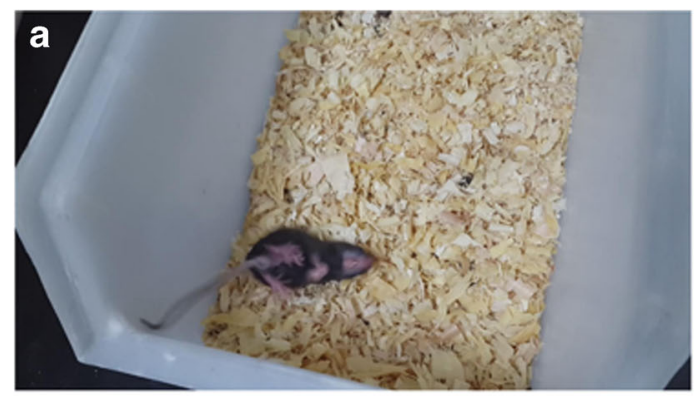

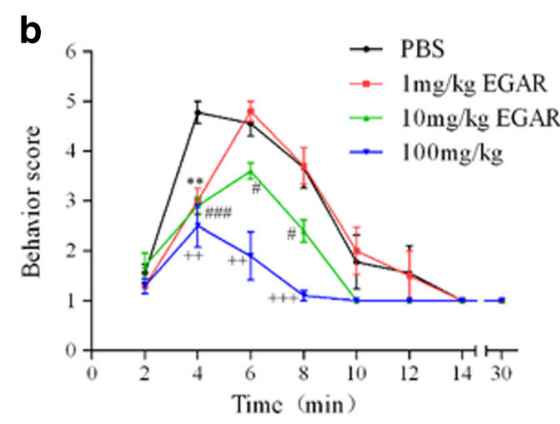

Fig. 8 Glu-Gly-Ala-Arg (EGAR) inhibits in vivo pentylenetetrazole (PTZ)-induced generalized convulsive seizures. (A) Photograph of a PTZ-induced seizure mouse. (B) Behavior score of 5 different groups with treatments of phosphate-buffered saline (PBS), and $1 \mathrm{mg} / \mathrm{kg}$, $10 \mathrm{mg} / \mathrm{kg}$, and $100 \mathrm{mg} / \mathrm{kg}$ EGAR during the test period of $30 \mathrm{~min}$. (C) Bar graph indicates quantification of the effects of PBS, and $1 \mathrm{mg} / \mathrm{kg}$,

plasticity. Usually, the trigger for these dynamic movements is the activation of NMDARs. While NMDAR antagonists inhibit these forms of synaptic plasticity, AMPAR antagonists do not impair synaptic plasticity and do not inhibit memory formation or retrieval.

Hippocampal hyperexcitability induced by magnesium reduction or removal is a well-suited in vitro model of epileptiform seizure activity to elucidate the cellular mechanisms that underlie epileptogenesis and the spontaneous recurrent epileptiform discharge activity associated with epilepsy [60]. The observed increase in spiking after the low magnesium treatment was significantly reduced after the addition of EGAR, indicating a rescuing effect of the agent. This result is consistent with the inhibition of AMPAR-mediated synaptic transmission contributing to the anticonvulsant effect of the drug. Thus, all of the above data suggest that the anticonvulsant activity of EGAR can be accounted for by a blockade of AMPARs.

EGAR reduced neuronal excitability and epileptiform activity in vitro, and we postulated, based on EGAR's actions in vitro, that EGAR may have anticonvulsant effects in vivo. PTZ is a chemical convulsant that reliably produces generalized convulsive seizures (clonic-tonic) when administered intraperitoneally. The rodent PTZ seizure model, which has been developed over $>60$ years, is a standard animal-seizure model according to the National Institute of Neurological

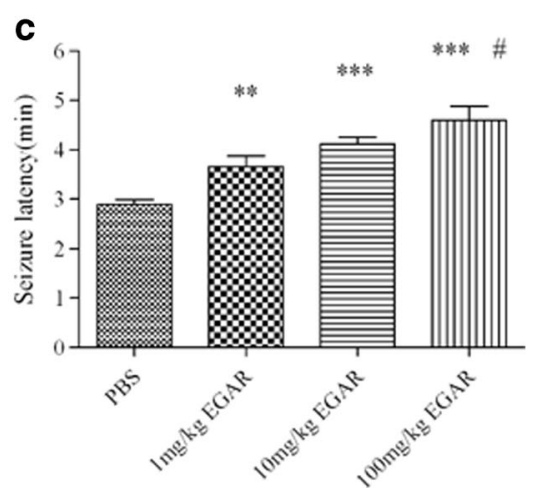

$10 \mathrm{mg} / \mathrm{kg}$ and $100 \mathrm{mg} / \mathrm{kg}$ EGAR on seizure latency. Differences between the control group and the groups treated with $1 \mathrm{mg} / \mathrm{kg}, 10 \mathrm{mg} / \mathrm{kg}$, and $100 \mathrm{mg} / \mathrm{kg}$ EGAR, respectively, are significant [**p $<0.03, * * * p<0.01$ representing EGAR-treated groups $v s$ control, ${ }^{*} p<0.05$ representing $1 \mathrm{mg} / \mathrm{kg}$ vs $100 \mathrm{mg} / \mathrm{kg}$, $t$-test $(n=6)]$. Error bars represent \pm SEM

Disorders and Stroke Anticonvulsant Drug Development Program [61], and it is one of the most widely animal seizure models employed in the search for antiepileptic drugs [62]. The marked anticonvulsant effects, observed after a systemic administration of EGAR in mice with PTZ-induced generalized seizures, can be related to its good bioavailability. The anticonvulsant potency of EGAR may be correlated to its lipophilicities, which positively influence the cellular permeability and therefore penetration of the blood-brain barrier. We conclude that EGAR is an anticonvulsant against acute seizures induced by PTZ, a convulsant, in vivo. Whether EGAR is effective against sporadic seizures in chronic epilepsy is unclear and requires further study.

In conclusion, the novel tetrapeptide, EGAR, reported in this study, possesses marked anticonvulsant activity. The in vivo antiseizure activity of EGAR in various aspects is consistent with its activity as an AMPAR antagonist in vitro. Thus, the PTZ model and hippocampal slice data show that EGAR has potential as an antiepileptic drug and it is noted that EGAR, different from other antiepileptic drugs that inhibit AMPAR activity, such as perampanel, may afford a broader range of treatment strategies because it is a naturally occurring peptide, which can be found in SSCP. As is reported, peptides provide an excellent starting point for new drug designing, considering their attractive pharmacological profile and intrinsic properties and because of their specificity, peptides have 
safety, tolerability, and efficacy profiles in human [63]. Dietary SSCP may become a natural diet therapy for epilepsy, which can improve tolerance and compliance of patients. In addition, gene delivery strategies [64] may enable EGAR expression in an epileptogenic cortical region refractory to conventional anticonvulsants that are not amenable to surgical treatment. However, EGAR may have intrinsic weaknesses of naturally occurring peptides, including poor chemical and physical stability, and a short circulating plasma half-life [63]. Therefore, the use of EGAR will depend upon the pharmacokinetics in humans. Thus, extensive evaluations are still needed to study its pharmacological properties and efficacy.

Required Author Forms Disclosure forms provided by the authors are available with the online version of this article.

\section{Compliance with Ethical Standards}

Funding and disclosure This work was supported by Science and Technology Planning Project of Guangdong Province (2013B010404011). The authors declare no conflict of interest.

\section{References}

1. Rogawski MA. AMPA receptors as a molecular target in epilepsy therapy. Acta Neurol Scand Suppl 2013(197):9-18.

2. Behr C, Goltzene MA, Kosmalski G, Hirsch E, Ryvlin P. Epidemiology of epilepsy. Rev Neurol 2016;172:27-36.

3. Beyenburg S, Stavem K, Schmidt D. Placebo-corrected efficacy of modern antiepileptic drugs for refractory epilepsy: systematic review and meta-analysis. Epilepsia 2010;51:7-26.

4. Barker-Haliski M, White HS. Glutamatergic mechanisms associated with seizures and epilepsy. Cold Spring Harb Perspect Med 2015;5:a022863.

5. Citraro R, Aiello R, Franco V, De Sarro G, Russo E. Targeting alpha-amino-3-hydroxyl-5-methyl-4-isoxazole-propionate receptors in epilepsy. Exp Opin Ther Targets 2014;18:319-334.

6. De Sarro G, Russo E, Ibbadu GF, Barreca ML, De Luca L, Chimirri A. AMPA receptor antagonists as potential anticonvulsant drugs. Curr Top Med Chem 2005;5:12.

7. Meldrum BS, Rogawski MA. Molecular targets for antiepileptic drug development. Neurotherapeutics 2007;4:18-61.

8. Chang PKY, Verbich D, McKinney RA. AMPA receptors as drug targets in neurological disease - advantages, caveats, and future outlook. Eur J Neurosci 2012;35:1908-1916.

9. Szénási G, Vegh M, Szabo G, et al. 2,3-Benzodiazepine-type AMPA receptor antagonists and their neuroprotective effects. Neurochem Int 2008;52:166-183.

10. Yamaguchi S-i, Donevan SD, Rogawski MA. Anticonvulsant activity of AMPA/kainate antagonists: comparison of GYKI 52466 and NBQX in maximal electroshock and chemoconvulsant seizure models. Epilepsy Res 1993;15:179-184.

11. Weiser T. AMPA receptor antagonists for the treatment of stroke. Curr Drug Target CNS Neurol Disord 2005;4:153-159.

12. Hanada T. The discovery and development of perampanel for the treatment of epilepsy. Exp Opin Drug Discov 2014;9:449-458.
13. Wu T, Nagaya Y, Hanada T. Pharmacodynamic and pharmacokinetic interactions of perampanel and other antiepileptic drugs in a rat amygdala kindling model. Seizure 2014;23:732-739.

14. Lemkul JA, Bevan DR. The role of molecular simulations in the development of inhibitors of amyloid $\beta$-peptide aggregation for the treatment of Alzheimer's disease. ACS Chem Neurosci 2012;3: 845-856.

15. Ahmed AH, Wang Q, Sondermann H, Oswald RE. Structure of the S1S2 glutamate binding domain of GluR3. Proteins 2009;75:628637.

16. Oswald RE. Ionotropic glutamate receptor recognition and activation. Adv Protein Chem 2004;68:313-349.

17. Najafian L, Babji AS. A review of fish-derived antioxidant and antimicrobial peptides: their production, assessment, and applications. Peptides 2012;33:178-185.

18. Sanjukta S, Rai AK. Production of bioactive peptides during soybean fermentation and their potential health benefits. Trends Food Sci Technol 2016;50:1-10.

19. Patil P, Mandal S, Tomar SK, Anand S. Food protein-derived bioactive peptides in management of type 2 diabetes. Eur $\mathrm{J}$ Nutr 2015;54:863-880

20. Mellander O. The physiological importance of the casein phosphopeptide calcium salts. II. Peroral calcium dosage of infants. Acta Soc Med Ups 1950;55:247-255.

21. Bouglé D, Bouhallab S. Dietary bioactive peptides: human studies. Crit Rev Food Sci Nutr 2015 Jun 11.

22. Li-Chan EC. Bioactive peptides and protein hydrolysates: research trends and challenges for application as nutraceuticals and functional food ingredients. Curr Opin Food Sci 2015;1:28-37.

23. Li Y, Shang J, Jiang Z, Zhang L, Su X. Regulation mechanism of peptides derived from sea cucumber (Apostichopus japonicas) for modulation of learning and memory. Food Sci Biotechnol 2016;25: 241-246.

24. Hartmann R, Meisel H. Food-derived peptides with biological activity: from research to food applications. Curr Opin Biotechnol 2007;18:163-169.

25. Duffy FJ, Verniere M, Devocelle M, Bernard E, Shields DC, Chubb AJ. CycloPs: generating virtual libraries of cyclized and constrained peptides including nonnatural amino acids. J Chem Inform Model 2011;51:829-836.

26. Wang L, Chen L, Yu M, et al. Discovering new mTOR inhibitors for cancer treatment through virtual screening methods and in vitro assays. Sci Rep 2016;6:18987.

27. Ge H, Wang Y, Li C, et al. Molecular dynamics-based virtual screening: accelerating the drug discovery process by highperformance computing. J Chem Inform Model 2013;53:27572764.

28. Sobolevsky AI, Rosconi MP, Gouaux E. X-ray structure, symmetry and mechanism of an AMPA-subtype glutamate receptor. Nature 2009;462:745-756.

29. Morris GM, Goodsell DS, Halliday RS, et al. Automated docking using a Lamarckian genetic algorithm and an empirical binding free energy function. J Comp Chem 1998;19:1639-1662.

30. Case D, Darden T, Cheatham I, et al. Amber 11.2010. University of California, San Francisco. 2010;5.

31. Duan Y, Wu C, Chowdhury S, et al. A point-charge force field for molecular mechanics simulations of proteins based on condensedphase quantum mechanical calculations. J Comp Chem 2003;24: 1999-2012.

32. Jorgensen WL, Chandrasekhar J, Madura JD, Impey RW, Klein ML. Comparison of simple potential functions for simulating liquid water. J Chem Phys 1983;79:926.

33. Bayly CI, Cieplak P, Cornell W, Kollman PA. A well-behaved electrostatic potential based method using charge restraints for deriving atomic charges: the RESP model. J Phys Chem 1993;97:1026910280 . 
34. Wang J, Wolf RM, Caldwell JW, Kollman PA, Case DA. Development and testing of a general amber force field. J Comp Chem 2004;25:1157-1174.

35. Darden T, York D, Pedersen L. Particle mesh Ewald: An N · $\log (\mathrm{N})$ method for Ewald sums in large systems. J Chem Phys 1993;98: 10089.

36. Ryckaert JP, Ciccotti G, Berendsen HJC. Numerical integration of the cartesian equations of motion of a system with constraints: molecular dynamics of $<\mathrm{i}>\mathrm{n}</ \mathrm{i}>$-alkanes. J Comp Phys 1977;23:327-341.

37. Fogolari F, Brigo A, Molinari H. Protocol for MM/PBSA molecular dynamics simulations of proteins. Biophys J 2003;85:159-166.

38. Agrawal S, Ojha RP, Maiti S. Energetics of the human Tel-22 quadruplex - telomestatin interaction: a molecular dynamics study. J Phys Chem B 2008;112:6828-6836.

39. Kollman PA, Massova I, Reyes C, et al. Calculating structures and free energies of complex molecules: combining molecular mechanics and continuum models. Acc Chem Res 2000;33:889-897.

40. Srinivasan J, Cheatham III TE, Cieplak P, Kollman PA, David A. Continuum solvent studies of the stability of DNA, RNA, and phosphoramidate-DNA helices. J Am Chem Soc 1998;120:94019409.

41. Chong LT, Duan Y, Wang L, Massova I, Kollman PA. Molecular dynamics and free-energy calculations applied to affinity maturation in antibody 48G7. Proc Natl Acad Sci U S A 1999;96:1433014335 .

42. Kavalali ET, Klingauf J, Tsien RW. Activity-dependent regulation of synaptic clustering in a hippocampal culture system. Proc Natl Acad Sci U S A 1999;96:12893-12900.

43. Hanada T, Hashizume Y, Tokuhara N, et al. Perampanel: A novel, orally active, noncompetitive AMPA-receptor antagonist that reduces seizure activity in rodent models of epilepsy. Epilepsia 2011;52:1331-1340

44. Koyama R, Tao K, Sasaki T, et al. GABAergic excitation after febrile seizures induces ectopic granule cells and adult epilepsy. Nat Med 2012;18:1271-1278.

45. Steiner T, Koellner G. Hydrogen bonds with $\pi$-acceptors in proteins: frequencies and role in stabilizing local 3D structures1. J Mol Biol 2001;305:535-557.

46. Leong JS, Jantzen SG, von Schalburg KR, et al. Salmo salar and Esox lucius full-length cDNA sequences reveal changes in evolutionary pressures on a post-tetraploidization genome. BMC Genomics 2010;11:279.

47. Andreassen R, Lunner S, Hoyheim B. Characterization of fulllength sequenced cDNA inserts (FLIcs) from Atlantic salmon (Salmo salar). BMC Genomics 2009;10:502.

48. Miller KM, Li S, Ming TJ, Kaukinen KH, Schulze AD. The salmonid MHC class I: more ancient loci uncovered. Immunogenetics 2006;58:571-589.
49. Huang TS, Olsvik PA, Krovel A, Tung HS, Torstensen BE. Stressinduced expression of protein disulfide isomerase associated 3 (PDIA3) in Atlantic salmon (Salmo salar L.). Comp Biochem Physiol B Biochem Mol Biol 2009;154:435-442.

50. Mangan PS, Kapur J. Factors underlying bursting behavior in a network of cultured hippocampal neurons exposed to zero magnesium. J Neurophysiol 2004;91:946-957.

51. Goodkin HP, Yeh JL, Kapur J. Status epilepticus increases the intracellular accumulation of GABAA receptors. J Neurosci 2005;25: 5511-5520.

52. Mano I, Lamed Y, Teichberg VI. A venus flytrap mechanism for activation and desensitization of alpha-amino-3-hydroxy-5-methyl4-isoxazole propionic acid receptors. J Biol Chem 1996;271: 15299-15302.

53. Armstrong N, Gouaux E. Mechanisms for activation and antagonism of an AMPA-sensitive glutamate receptor: crystal structures of the GluR2 ligand binding core. Neuron 2000;28:165-181.

54. $\mathrm{Lu} \mathrm{W}$, Shi Y, Jackson AC, et al. Subunit composition of synaptic AMPA receptors revealed by a single-cell genetic approach. Neuron 2009;62:254-268.

55. Kauer JS. Real-time imaging of evoked activity in local circuits of the salamander olfactory bulb. Nature 1988;331:166-168.

56. Perkel DJ, Nicoll RA. Evidence for all-or-none regulation of neurotransmitter release: implications for long-term potentiation. J Physiol 1993;471:481-500.

57. Namba T, Morimoto K, Sato K, Yamada N, Kuroda S. Antiepileptogenic and anticonvulsant effects of NBQX, a selective AMPA receptor antagonist, in the rat kindling model of epilepsy. Brain Res 1994;638:36-44.

58. Rogawski MA, Donevan SD. AMPA receptors in epilepsy and as targets for antiepileptic drugs. Adv Neurol 1999;79:947-963.

59. Tortorella A, Halonen T, Sahibzada N, Gale K. A crucial role of the alpha-amino-3-hydroxy-5-methylisoxazole-4-propionic acid subtype of glutamate receptors in piriform and perirhinal cortex for the initiation and propagation of limbic motor seizures. $\mathrm{J}$ Pharmacol Exp Ther 1997;280:1401-1405.

60. Guo F, Zhou PD, Gao QH, et al. Low-Mg(2+) treatment increases sensitivity of voltage-gated $\mathrm{Na}(+)$ channels to $\mathrm{Ca}(2+) /$ calmodulinmediated modulation in cultured hippocampal neurons. Am J Physiol Cell Physiol 2015;308:C594-C605.

61. Stables JP, Bertram EH, White HS, et al. Models for epilepsy and epileptogenesis: report from the NIH workshop, Bethesda, Maryland. Epilepsia 2002;43:1410-1420.

62. Loscher W. Critical review of current animal models of seizures and epilepsy used in the discovery and development of new antiepileptic drugs. Seizure 2011;20:359-368.

63. Fosgerau K, Hoffmann T. Peptide therapeutics: current status and future directions. Drug Discov Today 2015;20:122-128.

64. Muller FJ, Snyder EY, Loring JF. Gene therapy: can neural stem cells deliver? Nat Rev Neurosci 2006;7:75-84. 